Kom, 2017, vol. VI (3) : 31-47

UDC: $117: 28-1$

117 Мула Садра Ширази

DOI: $10.5937 / \mathrm{kom} 1703031 \mathrm{H}$

Original scientific paper

\title{
The Primal Matter and the All-Pervasive IMPOVERISHMENT OF THE MATERIAL WORLD
}

\author{
Shiraz Husain Agha \\ Faculty of Philosophy, Al-Mustafa International University, \\ Qom, I. R. Iran
}

One of the most important discussions in philosophy is concerned with the Primal Matter. It is also a discussion which has existed from the very conception of philosophy. The genesis of this concept goes back to ancient Greece where philosophers used to debate the original source of the physical universe. Aristotle was of the opinion that this was nothing but the Primal Matter. The Primal Matter is a substance in which the physical form, the specific forms and the accidents of these forms exist. It is what receives these beings. It is also pure potentiality. In and of itself, it lacks actuality. However, when it accepts the forms of physical beings, it partakes of the actuality of what it receives. The Primal Matter is the termination of the Arc of Descent and the beginning of the Arc of Ascent. In a sense, this pure potentiality reflects the Necessary Being, which is a pure actuality. The Primal Matter needs form for actuality. Conversely, form needs matter for individuation and specification, which is accomplished through accidents that this matter is the recipient of. Both of these beings need the Active Intellect which is the agent of their existence. Form and matter are united with one another in the external world, according to Mulla Sadra. What is more, impoverishment is contained within the very existence of all of the beings of the material word, regardless of what they are. This is one of the greatest conclusions that the Transcendent Wisdom of Mulla Sadra was able to discover.

Keywords: Primal Matter, Physical Form, Specific Form, Active Intellect, impoverishment, material world 


\section{Introduction}

When a human being is born, he finds himself within the material world. In fact, not only is the human being surrounded by material beings, he is even attached to one, i.e. his physical body. In fact, in the view of some philosophers, man is originally a purely physical being. It is only later on, by means of substantial motion, that man attains a level of immateriality. Also, man's primary tools for the acquisition of knowledge are the senses. His other faculties of knowledge blossom or are perfected only later on. These senses can only grasp sensible objects. They are incapable of understanding immaterial beings. For these and many other reasons man learns to give primary importance to physical beings. This is true to the extent that he may even doubt the possibility of a being immaterial in nature. Thus, when he conceives of God, he thinks of Him as a physical being, confined to space and time. Taken to an extreme, this tendency eventually leads to a denial of every kind of immaterial being whatsoever. It is only obvious what preposterous conclusions this tendency may lead to. No one can legitimately believe in an Afterlife without the belief in the possibility of a being, such as the human soul, that is immaterial in nature. It was with keeping all of these misgivings in mind that Muslim philosophers allocated a great portion of their philosophical pursuits to the discovery of the properties of the material world and the physical beings that exist within it. One of the most important of these discussions is the one that concerns the Primal Matter. So important is this discussion that we see its shadow being cast upon all other discussions contained within Islamic philosophy, theology and mysticism. Actually, no one can claim to have any sort of expertise about these subjects without a proper understanding of the properties of the Primal Matter. In this article, after an overview of some of the most essential distinctions of the Primal Matter, we will briefly look into one of the most significant conclusions that one can derive from them, i.e. the idea that the material world is filled with the quality of impoverishment. There is no self-sufficiency in the physical world. Although this is a quality that exists in all beings other than the Necessary Being, it is something that is accentuated in the material world. The ultimate spiritual conclusion that we can derive from this philosophical fact is that as human beings we should not look towards this world and the beings contained within it for succor.

\section{The Primal Matter}

\subsection{Definition}

Before we can enter the main subject of this paper it is necessary to first define the primal matter and then to prove its existence. Regarding the first 
topic, it is possible to say that the Primal matter is a substance that is pure potentiality (Kurd Firuzjai 2007: 353). It possesses no actuality on its own. If this seems to contradict the idea that everything that exists is in a state of actuality, then this contradiction can be resolved by keeping in mind the fact that the Primal Matter exists only when it is coupled with form. Its actuality stems from the actuality which form possesses. It is the end of the series of effects that stems from God. In other words, it is the termination of the Arc of Descent and also the beginning of the Arc of Ascent. It resembles God in that while God is pure actuality, the primal matter is - essentially - pure potentiality and thus, the two are mirror images of one another in this sense. With the primal matter, or the hyle, the beings that stem from God cease to exist and time begins. This is because time is the measure of movement. Movement is the gradual journey from potentiality to actuality. Now, it is the primal matter that is the locus in which all potentiality resides. Thus, without primal matter there would be no potentiality or movement. In other words, the material world begins with the Primal Matter and a series of changes come about in it that eventually lead to the creation of the human soul, which begins its journey toward God through the acquisition of knowledge.

\subsection{Proofs for the existence of the Primal Matter}

\subsubsection{The Argument from Connection and Disconnection}

The first argument for the existence of the primal matter is a famous proof and the one that is most relied upon by philosophers. The argument rests upon the disjunction between connection and disconnection and is composed of the following premises:

$1^{\text {st }}$ Premise: Every physical body is connected, one and united. In other words, every physical body is a whole.

$2^{\text {nd }}$ Premise: Every physical body has the potentiality to be divided or disconnected. In other words, it is possible to divide it into halves, fourths and so on.

$3^{\text {rd }}$ Premise: Following the division, two or more new dimensions come into existence. In other words, if before the division the physical body had one specific dimension, after the division the physical body comes to possess two or more new dimensions.

$4^{\text {th }}$ premise: By being divided the physical body accepts this division. In other words, it is not true to say that by being divided the previous physical body ceases to exist altogether and that something completely new comes into existence. Rather, there is something in the physical body that accepts the division and the two new dimensions. 
$5^{\text {th }}$ Premise: It is impossible for us to say that the thing which has accepted the division or the new dimensions is the previous connection or dimension that existed before the division took place. This is because with the division the connection that had previously existed as well as the previous dimensions have terminated and no longer exist. Now, it is clear that if something wants to accept something else, it is necessary for that thing to exist first of all and then to accept that thing following this. In other words, it is not possible to say that by accepting the thing, the thing accepting ceases to exist.

$6^{\text {th }}$ Premise: It is also not possible for us to say that the thing that has accepted the division and the new dimensions is the bodily form (as-surah al-jismiyyah). This is because the relation between the bodily form and its specific dimensions is a type of unity and it is impossible for the bodily form to exist without and separately from the specific dimensions that make it specific. The reason for this is that nothing exists in the external world in an unspecified form. Rather, if something exists outside our mind then it will always be specific and definite. To put it better, the bodily form is defined as an unspecified connection and unity and it is impossible for something to accept its opposite (i.e. disconnection and separation).

Conclusion: Therefore, there has to be something other than the bodily form existing in the physical body that accepts the division and the new dimensions and which is not one with the previous dimensions so that it might cease to exist when the previous dimensions cease to. Also, it must be such that it is not defined as some unspecified connection which could accept the opposite of the same, i.e. disconnection and separation (Ibn Sina 2000: 500).

\subsubsection{The Argument from Potentiality and Actuality}

The next proof for the existence of the primal matter is the argument from potentiality and actuality. This proof rests upon the following premises:

$1^{\text {st }}$ premise: Every physical body is actually something. For example, it may be water, fire, air or earth.

$2^{\text {nd }}$ premise: Every physical body has the potential to become something else. For example, if it is an instance of water, then it may have the potential to become air by being vaporized.

$3^{\text {rd }}$ premise: Potentiality is tantamount to non-existence and actuality is synonymous to existence. For example, if something is actually water, then water exists; and if it has the possibility to become air, then at the moment air does not exist. 
$4^{\text {th }}$ premise: The next premise, which is self-evident, is that existence and non-existence do not combine into one instance.

$5^{\text {th }}$ premise: Potentiality is a quality and therefore there must be something that is qualified by it.

$6^{\text {th }}$ premise: However, it is impossible for the bodily form (as-surah al-jismiyyah) or the accidents inherent in the bodily form to be qualified by the potential of the physical body. This is because, based upon the $3^{\text {rd }}$ and $4^{\text {th }}$ premise, it would lead to non-existence and potentiality to combine with existence and actuality (i.e. the bodily form and its accidents).

Conclusion: Therefore, there has to be another locus in the physical body that is the locus of its potential.

There are various other arguments for the existence of the Primal Matter that we will not consider here for the sake of brevity. For an account of these arguments, we refer the reader to more detailed texts (Nabawiyyan 1987: II/475-502; Khafri 2000: 59-60) which have dealt with this issue.

\subsection{The Relation Between the Primal Matter and the Bodily Form}

\subsubsection{The Unity or Disunity of the Primal Matter and the Bodily Form}

Let us now turn to another important discussion regarding the primal matter. This concerns the relation between the primal matter and the bodily form. Here, there is a difference of opinion between Ibn Sina and Mulla Sadra regarding this relationship. The former is of the opinion that the relation between the two is that of two separate things. In other words, the primal matter and the bodily forms are two concepts that have meanings in the external world. However, the meanings of these two concepts do not have one instance in the external world. In simpler terms, the mind abstracts these two concepts from two distinct instances in the external world.

However, Mulla Sadra was of the opinion that the relation between these two concepts is one of unity. In other words, these are two concepts that possess two meanings in the external world. These two meanings exist in one instance. This means that the mind abstracts these two concepts from one instance in the external world.

This difference of opinion stems from a more fundamental difference between these two schools of thought, and that is whether or not it is possible for two concepts that have distinct meanings to possess one single instance in the external world. We can see this difference of opinion show up in a number of other topics. Hereunder we will list some of the instances in which this difference is manifested. However, before we do this it is necessary 
for us to present an introduction that can help clarify what we have just stated. This we will do in the form of four important points.

The First Point

We can consider four existences [i.e. for levels of existence] for everything: An external existence, a mental existence, a verbal existence and a written existence.

For example, water possesses a real existence that is its external existence and also has a mental existence that is its mental picture or form. Aside from these two, water also has a verbal existence that is the word formed with the letters $w, a, t, e$ and $r$, which is usually used when we speak. Finally, there is the written existence of water that comes into being after [the word] is written down. Mental existence signifies external existence through an existential indication - or essential indication - that is not conventional [i.e. artificial] in nature. On the other hand, verbal and written existence will indicate external existence if and only if the word in question has been [artificially] coined to denote such a real being.

In order to explain, the mental picture essentially possesses the characteristic of depicting reality. This is to so true that this characteristic cannot be taken away from it. Even if the thing that it is depicting does not really exist, the mental picture will still have the distinction of depicting and portraying it. For example, say on a hot summer day the sun is shinning directly on the ground [at a distance]. A picture is formed in our mind that indicates to us that there is water on the road [i.e. the phenomenon that is a mirage]. However, after we move forward and reach the place where we thought we saw water we find that there is no water there. Here, even though the mental picture in our minds depicted water in the external world, in reality there was no such water at all. This is a proof that the mental picture essentially possesses the quality of depicting the world outside it - whether this picture has arisen from its real source in the external world (i.e. the real water in our example) or it has been created by other factors in our minds; but it is deceptive in the sense that it depicts something that does not really exist. In any case, this quality of displaying reality is not something that depends upon our intention, conventions and our likes and dislikes. It is a distinction that accompanies the mental existence, whether we like it or not.

However, the verbal existence (i.e. the spoken word) and the written existence signify the external reality because we have concurred that they should do so. No spoken or written word, in and of itself (i.e. essentially), could signify the external reality of water before it we came to a consensus that whenever we hear or see a particular word [for example, "water"] we 
should understand from it the real existence of water. It is for this reason that in the Persian language the word "aab" has been coined to mean water (i.e. the real existence of water), although it is clear that people could have chosen any other word to designate it. In the same way, in other languages other words have been coined to point towards the reality of water.

\section{The Second Point}

We find ourselves face to face with three terms within the parameters of acquired knowledge: Concept, meaning and extension.

"Concept" is the mental existence and is [like] a window by means of which we can see the external world. This window, however, is not wide enough to show us all of reality. Rather, by means of every window [that is a concept] we can see only a portion of reality. In order to see reality in its totality we must open many windows from different angles in its direction and, by using various concepts, we must obtain a complete comprehension of reality.

"Meaning" is the portion of reality that a specific window or concept shows us. For example, consider water that has filled up a container with the volume of 9 cubic meters. Assume that this water has also been heated by the sun. Right now, in the external world there exists warm water with the volume of 9 cubic meters. When we look at this reality by means of the concept "water" then only one dimension of this reality, that is the dimension of its being water and not, lets say, earth, has been understood by us. On the other hand, its other dimensions, such as the fact that it is warm, that its volume of 9 cubic meters or other things related to it, have still not been comprehended by us [from the viewpoint of this concept in particular]. In order to become familiar with each one of the other dimensions of this reality we must utilize new concepts and [open other] windows so that, in the end, we may obtain a more comprehensive knowledge of it.

Finally, "extension" is the reality that exists in the external world in its entirety and with all of the dimensions that it possesses; dimensions each one of which is understood by means of a separate concept. Of course, it is possible that there may be many aspects of this external reality (i.e. extension) that still have not been discovered by human beings. Therefore, even though the extension is only one being, it is the existence of all of the "meanings" in the external world which various concepts depict for us. What is more, it is the existence of numerous other "meanings" for which we still have not formed a concept, due to the fact that they have yet to be understood. For example, the warm water [that was mentioned above] with the volume of 9 cubic meters is an extension which is not more than one thing, and yet, it is 
the external existence of [numerous] meanings such as: water, warmth and 9 cubic meters; and, as we previously stated, it is also the existence of many other meanings that are amongst the countless facts that we do not know about water.

Keeping in mind the matters that have just been explained, when we say that the water in the external world is the existence of the concept (i.e. the existence as knowledge) of water we are simply looking at the external existence of water, but have not stated anything with regards to the existence of its other dimensions, such as its being warm or being 9 cubic meters in volume. Therefore, only its existence as water is the external existence of the concept of water, while its being warm or 9 cubic meters in volume are external existences of two other concepts; that is to say, the concept of being warm and having the volume of 9 cubic meters.

\section{The Third Point}

There are two types of depiction: a man-made (conventional) depiction and a natural (essential) depiction.

The man-made depiction is that in which the depiction of the thing depicting (haki) in relation to the thing that is being depicted (mahki) depends upon a resolution and it is not true that the thing depicting (haki) displays the thing being depicted (mahki) on its own and without the need for a previous resolution. For example, a word that is coined to indicate something does not display the thing it denotes by itself (i.e. essentially) and unless and until there is no resolution at play a given word such as "water" will not denote the colorless, odorless and tasteless entity that exists in nature (i.e. real water). It is instances such as this that the one who has made the resolution [that the given word indicates the given meaning] must [1] first comprehend the thing depicting [(i.e. the given word)] as well as [2] the reality that is being depicted and [3] following this make the resolution that the word should depict and indicate the thing that has to be depicted.

[However,] natural depiction is that in which the act of depicting (hikayah) of the thing depicting (haki) is essential to it and does not stand in need of any resolution. In this type of depiction, anytime that the thing depicting (haki) comes into existence, it will automatically (i.e. essentially) show the reality ${ }^{1}$ that it depicts (mahki). In this regards, it does not matter whether that reality has external existence, its existence in the external world

1 Here, "reality" is not tantamount to existence. Rather, the reality of everything is harmonious with that thing: [So,] the reality of existence is its existence and the reality of non-existence or something that is impossible is its' [real] non-existence. Technically speaking, the reality of everything is in line with that thing itself. 
is uncertain (in the manner in which physicists have doubted in the external existence of colors) or it does not, fundamentally speaking, exist in the external world. Its external existence may even be impossible. The manner in which concepts depict the realities that they depict is of this nature and, as was previously mentioned, every concept essentially depicts the reality that it depicts. The type of depiction (hikayah) that belongs to concepts is something that can be fathomed through knowledge by presence and everyone can witness such a situation by referring to the concepts that exist in his mind. In this way, mental concepts can even depict impossible things or those that do not exist and show them [to the mind]. This is so even though these types of things do not, fundamentally speaking, exist in the external world. They do not possess a material and sensible existence nor an immaterial and non-sensible one. Even though this is true, the ideas of such things exist in our minds, such as the concept of the combination of contradictions, the concept of a vicious circle and the concept of an infinite regress, none of which can exist in the external world. Based upon the essential distinction of every concept, these concepts depict the things they depict [(i.e. their instances in the external world)]. Therefore, at least those concepts that depict impossible things are formed within our minds without the need of any [previous] relation with their instances [in the external world], instances we are not capable of forming a relation with given the fact that they basically do not exist.

\section{The Fourth Point}

Let us now turn to the instances in which this fundamental difference of opinion (i.e. the possibility for two concepts to have two meanings that possess a single instance in the external world) has been manifested:

1. The unity of God's attributes with His Essence and with one another.

2. The unity of the soul and its faculties.

3. The unity of the knower and the mental form.

4. The unity of the knower and the Active Intellect.

5. The unity of matter and form.

6. The unity of existence and quiddity.

7. The unity of the agent and its effect.

It seems that the reason why Ibn Sina adhered to the impossibility of such a unity was that it would lead to one thing being two things. This seems to be the crux of the demonstrations that he stated in numerous places to 
substantiate this claim. Having said this, let us turn briefly to the proof of Mulla Sadra for the unity of matter and the bodily form. Aside from the essential possibility of such a unity in the eyes of Mulla Sadra, he presented numerous proofs to demonstrate the unity of matter and form. One of these proofs rests upon the idea that the mind predicates one of them for the other. Such a predication, he says, would be impossible if they were two distinct beings in the external world. Another proof rests upon the idea that matter is pure potentiality and that everything existing in the external world must be actual. Therefore, in order for it to exist it must be united with something (such as the bodily form) that could make it secondarily actual.

Before we enter the next discussion, it is necessary to mention, in passing, a very important point. Some contemporary scholars are of the opinion that the unity of matter and form that Mulla Sadra spoke of is not like the unity of the Essence of God and His attributes. Rather, it resembles the unity of substance and accident or the intellect and the intelligible. In order to explain, there are two ways in which two things can unify together. In one case, two things unite together in such a manner that they both exist at one level of existence. However, sometimes two beings unite in such a manner that one of them becomes a lower degree of the other. In other words, one of the beings is present at the level of the existence of the other but not vice versa. However, in the first case both beings are present at the level of existence of the other. According to some modern commentators of the Transcendent Wisdom, the relation between the Primal Matter and form belongs to the second category. The reason for this is that if the primal matter - that is potentiality - united with form - that is actuality - at one level, it would entail that potentiality and actuality would unite at one level. This is not only a contradiction, but it also goes against one of the premises of one of the arguments of the primal matter, i.e. the argument by means of potentiality and actuality. In other words, the Primal Matter is a lower degree of the existence of form. At this lower level, form lacks actuality. For this reason, a contradiction does not occur due to the unification of potentiality and actuality. It is only at its own higher level of existence that form has actuality. In any case, this is a topic that requires an independent investigation.

\subsubsection{The Mutual Dependency between the Primal Matter and the Bodily Form}

\subsubsection{Proof:}

This idea can be proven in a number of different ways. One argument is as follows: 
$1^{\text {st }}$ premise: As we just stated, the relation between the primal matter and the bodily form is one of a unity.

$2^{\text {nd }}$ premise: If the relation between matter and form is one of a unity, then they will form a real composite. If they form a real composition, then it is necessary that there be a dependency between the two. This is because in every real composition there is a mutual dependency between the parts of this composition. The reason for this is that if the parts of a real composition did not mutually need one another, they would not form a real unity and something new would not come into being by their composition; rather, the effect of their composition would simply be the sum total of their individual parts (Tabatabai 2010: 96).

Some have gone to the extent of saying that the mutual dependency of the parts of a real composition is something self-evident, not needing a demonstration to substantiate it (Sabziwari 1991: IV/104).

Nevertheless, in the Metaphysics of the al-Shifa (Ibn Sina 1997: 85-91), Ibn Sina mentions a couple of his own proofs for the mutual dependency of these two beings. He separately discusses why matter cannot exist without form and why form cannot exist without matter. For brevity's sake, we will overlook these and refer our reader to the aforementioned work for further research.

\subsubsection{What do the Primal Matter and the Bodily Form Need Each Other for?}

Now it is necessary to delineate what exactly these two need each other for. The bodily form needs matter in order to be qualified by accidents that specify it. The reason for this is that nothing in this world exists in an unspecified manner; rather, everything in the external world is specific and definite. However, in order for the bodily form to be possess individuality, it is necessary for it to be qualified by accidents that take it out of the universality that it possesses and make it individual. Now, the bodily form, being actual, cannot accept these accidents on its own. This is because acceptance implies the lack of and non-existence of the thing being accepted. This is while the bodily form possesses actuality, which is equal to existence. Now, existence and non-existence cannot combine together. This leads us to the conclusion that it is matter that must accept these accidents for the bodily form.

Matter, in turn, needs the bodily form. However, it needs the bodily form, as well as the specific forms of each species, in order exist. The reason for this is that matter pure potentiality. Now, everything that exists in the 
external world is actual. Thus, in order for matter to exist, it must unite with the bodily form and come to possess actuality through it. However, with regards to the specific forms, it is not necessary for it to unite with one specific form in order to exist. Rather, any one of them that it unites with is enough (Tabatabai 2007: 118).

\subsection{The Agent of the Primal Matter}

Let us now turn to another important discussion regarding the primal matter. This is regarding the agent of its existence. What is the cause of the primal matter? More specifically, what is the agent that grants it existence? Does this agent work alone or does it have a tool that it uses to uphold the existence of the primal matter? Here the philosophers believe that the agent of the primal matter is an immaterial intellect that brings it into existence. This "intellect" should not be confused with the "intellect" that is one of the faculties of man and whose function is the conception of universal concepts and propositions. Rather, this "intellect" is a substance that is not connected to matter in any other way than the one in which an agent is connected to its effect. However, they say that it does not work alone; rather, it uses the bodily form to uphold its existence. Thus, the primal matter is one of the reasons why philosophers have come to adhere to the idea of an immaterial intellect. Let us examine this proof in detail.

$1^{\text {st }}$ premise: This premise rests upon the idea that the primal matter is a possible being.

$2^{\text {nd }}$ premise: Every possible being needs a cause at least one of the parts of which is the agent of the possible being.

$3^{\text {rd }}$ premise: The agent of the primal matter can be one of the following: 1 . The bodily form. 2. A soul. 3. God. 4. An immaterial intellect.

$4^{\text {th }}$ premise: However, it is impossible for the agent of the primal matter to be the bodily form or the soul. This is because in order for something to bring something else into existence (i.e. serve as the agent of that thing), it is necessary for that agent to exist in the first place. How could it be possible for something not to exist and at the same time to grant existence to something else? In general, something must have something else in order for it to grant it to something else. Now, in order for something to exist, it is necessary for that thing to be specific. This is because everything that exists in the external world is specific. Now, in order for the soul and the bodily form to be specific, it is necessary for them to have certain accidents in addition to their essence. In order for them to possess these accidents they have to have some connection to the pri- 
mal matter that is the locus of these accidents or which give them the potential accept these accidents (such as is the case with the soul, which accepts accidents that make it specific, but needs matter that gives it the potential to accept the same).

However, there is another fundamental reason why the bodily form cannot create the primal matter. In order for the bodily form to have an effect upon the material world, it is necessary for it to come into a spatial relation with the thing it wants to have effect upon. For example, if fire is to heat something up, it is necessary for the thing that it is to heat up to be spatially close to it. The reason for this principle - aside from experience - is that the bodily form or a specific form cannot exist without a specific spatial relation with the things that surround it. Otherwise, it would mean that everything could come into existence and would come into existence in any situation whatsoever. This clearly goes against experience. When we look at the material world, we see that material beings only come into existence when they come into a specific relation with the things that surround them. If water is placed beside fire, then fire can exist, but if it is placed upon it the fire will be extinguished. So, the existence of every material form depends upon a specific spatial relationship with the things around it. Now, granting existence depends upon having existence - as was just mentioned. Thus, granting existence would also depend upon this specific spatial relation. Thus, until a specific spatial relationship is not established with its environment the form will neither exist nor grant existence. However, in this particular case the bodily form wants to grant existence to the Primal Matter. Keeping the above principle in mind, this would imply that it would have to come into a specific spatial relationship with it before it can do so. However, before something actually exists, it is impossible for something to establish a spatial relation with it. Thus, form cannot have a spatial relationship with the Primal Matter before it exists and it cannot therefore have an effect upon it - that is, in this case, the granting of existence to it.

$5^{\text {th }}$ premise: It is also not possible for the cause of the primal matter to be God in a direct manner. The reason for this is that God, being one and simple, cannot bring the primal matter, which possesses a certain multiplicity, into existence. This idea rests upon the famous Principle of the One, which states that a being that is one and simple cannot bring something into existence that is multiple or composed of parts (at-Tusi 2007: II/787-788).

Conclusion: Now that the other options for the agent of the primal matter have been negated, we can conclude that its agent is an immaterial intellect. 
However, it must be stated that the nature of this agency is different depending upon the philosophical system we adhere to. According to the Peripatetic philosophy, the Active Intellect is a real agent that grants existence to the beings of the sub-lunar realm. The only thing is that it does so with the existential "permission" of God. However, according to Mulla Sadra, the Active Intellect - or any other being for that matter - cannot grant existence to anything. In other words, nothing other than God is really an agent - in the philosophical meaning of this term. The reason for this is that agency is the sole prerogative of a being that possesses existence. If it does not possess existence, then it will not be able to grant it to something else. However, according to the Transcendent Philosophy, the possible beings lack existence. This is due to their copulative nature. Being relations does not allow them to possess anything independently. So, they are not really agents of existence. Rather, they are simply "channels of God's agency" (majari al-faydh).

\section{The Various Names of the Primal Matter}

The Primal matter has various names each of which points to a different dimension of this being. It is called the "Hayula" from the point of view that it can potentially receive a form. From the point of view according to which composition begins from it, the primal matter is called "unsur". Conversely, since analysis terminates with the primal matter, it is called "ustuqus". This is because matter is simple and it is not composed of matter and form. It is called a "mowdhu" from the point of view according to which it actually receives a form. Also, it is called "tinat" and "maddah" from the point of view according to which it is something that is common to the different forms it receives (Sabziwari 1991: IV/168). Of course, as some have accurately stated, sometimes these names are used interchangeably with one another. So, for example, the respective matters of the heavenly spheres are called their "Hayula" even though they never have the potentiality for any form. Also, they are called their "matters" (maddah) even though each of the spheres has its own matter and none of them are common to more than one heavenly sphere (Shirazi 1981: II/231).

\section{The Primal Matter and the All-Pervasive Need of the Material World}

Now that all of this has been established, let us turn to the main conclusion of our discussion. This is the all-pervasive need of the material world. The material world is filled with impoverishment. First of all, by the material world we mean the world in which the primal matter and the bodily form 
exist. We intend by "all-pervasive need" the idea that no being in the material world is independent, but that, rather, need and dependency surround each and every being in this world. We can demonstrate this idea based upon what we have established in the previous section. However, in order to give a logical form to our argument, we can state the instances of this need in the following manner:

1. The First Instance: Every physical body is composed of two substances: the Primal matter and the bodily form. We have previously demonstrated the fact that the primal matter depends upon the bodily form to possess actuality. This is because in and of itself, the primal matter is pure potentiality. However, every being in the external world is actual. Thus, the primal matter needs the bodily form in order to exist.

2. The Second Instance: the Primal matter also needs the immaterial intellect in order to exist. The reason for this is that the immaterial intellect is the agent of the primal matter.

3. The Third Instance: The bodily form needs the primal matter for its individuation.

4. The Fourth Instance: The bodily form needs the immaterial intellect in order to bring it into existence.

From these four points we can conclude that there is need and dependency within the very substance of physical bodies. This need is not only for something that lies outside them (i.e. the immaterial intellect), but also for something that lies within them (i.e. matter or form as the case may be). If we add to this notion the idea that there is no body that is devoid of matter and form, we will come to the conclusion that the entire physical world is sheer need and dependency.

However, there is an even more profound impoverishment at play here. This impoverishment lies within the very existence of physical bodies and their accidents. However, this type of impoverishment is not something that can be established based upon the principles of the Peripatetic philosophy. Rather, it is something that must be established upon the foundations of the Transcendent Wisdom of Mulla Sadra. The way that this has been established is in the following manner:

$1^{\text {st }}$ premise: The existence of an effect depends upon the existence of its cause.

$2^{\text {nd }}$ premise: This dependency exists either within the essence of the existence of the effect or outside of it. 
$3^{\text {rd }}$ premise: However, if this dependency existed outside the essence of the existence of the effect, then it would mean that essentially the effect would not depend upon its cause.

$4^{\text {th }}$ premise: Yet, the essence of the existence of the effect does depend upon its cause. Therefore, dependency lies within the very essence of the existence of the effect.

$5^{\text {th }}$ premise: However, dependency is the relation between the effect and its cause.

Conclusion: The existence of the effect is a copulative being, i.e. a relation, and lacks all independence in relation to its cause.

With this philosophical foundation in mind we can better understand those verses of the Holy Quran that state:

"There is nothing but that does celebrate His praise" (Qur'an 44: 17).

In order to explain, if the material world is sheer need and dependency, then there is something toward which it turns. In other words, it seeks out the thing that can fulfill its needs. At a very basic level these are the immaterial intellects. However, keeping in mind the idea that these are themselves dependent on God, we can come to the conclusion that in the end the material world depends upon God to fulfill its needs. This existential focus that the material world displays is its act of praying to God, in the philosophical meaning of the term. We can thus interpret the above mentioned verse of the Holy Qur'an in light of the philosophical foundations that we have laid down in this article.

Received: September $22^{\text {nd }}, 2017$.

Accepted: October $24^{\text {th }}, 2017$.

\section{Bibliography}

Holy Qur'an.

Ibn Sina, Husain ibn Abdullah (1997), al-Ilahiyyat min Kitab al-Shifa, Qom, Bustan-e Kitab.

Ibn Sina, Husain ibn Abdullah (2000), al-Najat min al-Gharq fi Bahr al-Dhalalat, Tehran, Intisharat-e Danishgah-e Tehran. 
Khafri, Shams al-Din Muhammad ibn Ahmad (2000), Risalah fi Tahqiq al-Hayula, Mashhad, Danishgah Ulum Islami Radhawi.

Kurd Firuzjai, Yar-Ali (2007), Nouawarihaye Falsafeye Islami dar Qalamrowe Ma Bad al-Tabiat be Riwayate Ibn Sina, Qom, Muassasah Amuzishi wa Pajuhishi Imam Khomeini.

Nabawiyan, Sayyid Muhammad Mahdi (1987), Jastarhayi dar Falsafaye Islami, Qom, Majma' Ali Hikmat Islami.

Shirazi, Sadr al-Din Muhammad ibn Ibrahim (1981), al-Hikmat al-Mutaaliyah $f i$ al-Asfar al-Arba'ah al-Aqliyyah (Asfar), Beirut, Daru Ihya al-Turath.

Sabziwari, Mulla Hadi (1991), Sharh al-Manzumah, Tehran, Nashre Nab.

Tabatabai, Sayyid Muhammad Husain (2007), Nihayat al-Hikmah, Qom, Muassasah Amuzishi wa Pajuhishi Imam Khomeini.

Tabatabai, Sayyid Muhammad Husain (2010), Bidayat al-Hikmah, Qom, Jamiah al-Mudarrisin.

al-Tusi, Nasir al-Din (2007), Sharh al-Isharat wa al-Tanbihat, Qom, Bustan-e Kitab. 